\title{
Importance of the lateral parabrachial nucleus to sodium balance in fluid-depleted rats
}

\author{
K.A. Cabral ${ }^{\mathrm{a}}$, C.A.F. Andrade ${ }^{\mathrm{b}, *}$ \\ a Graduate Program in Physiology of the Brazilian Physiological Society, Unifal-MG, Alfenas, MG, Brazil \\ ${ }^{\mathrm{b}}$ Department of Physiology and Pathology, School of Dentistry, UNESP, Araraquara, SP 14801-903, Brazil
}

\section{A R T I C L E I N F O}

\section{Article history:}

Received 12 February 2016

Received in revised form 13 May 2016

Accepted 17 May 2016

Available online 6 June 2016

\section{Keywords:}

Sodium

Dehydration

Natriuresis

Alpha 2 -adrenoceptor

Hindbrain

\begin{abstract}
A B S T R A C T
The lateral parabrachial nucleus (LPBN) exerts an important inhibitory influence for the control of sodium and water intake. However, the importance of LPBN on renal responses and cardiovascular changes during extracellular dehydration are still unknown. Here we investigated the effects of bilateral injections of moxonidine (alpha 2 -adrenergic and imidazoline receptor agonist) on renal and cardiovascular changes in fluid-depleted rats. Male Wistar rats ( $n=4-8$ per group) with bilateral stainless steel guide-cannulas implanted into the LPBN were treated with subcutaneous furosemide $(10 \mathrm{mg} / \mathrm{kg})+$ captopril $(5 \mathrm{mg} / \mathrm{kg})$ to induce fluid depletion. Forty-five min later vehicle or moxonidine $(0.5 \mathrm{nmol} / 0.2 \mu \mathrm{l})$ were bilaterally injected into the LPBN. In fluid-depleted rats, moxonidine produced strong $0.3 \mathrm{M} \mathrm{NaCl}$ and water intake without noticeable changes in cardiovascular parameters. Moxonidine did not change sodium excretion $(488 \pm 135$, vs. vehicle: $376 \pm 75 \mu \mathrm{Eq} / 1 \mathrm{~h})$ or urinary volume $(2.5 \pm 0.7$, vs. vehicle: $2.5 \pm 0.3 \mathrm{ml} / 1 \mathrm{~h})$ in fluid-depleted rats without access to fluids for rehydration. However, moxonidine decreased natriuresis ( $462 \pm 127$, vs. vehicle: $888 \pm 122 \mu \mathrm{Eq} / 1 \mathrm{~h}$ ) and diuresis $(2.5 \pm 0.5$, vs. vehicle: $4.5 \pm 0.5 \mathrm{ml} / 1 \mathrm{~h}) \mathrm{in}$ fluid-depleted rats submitted to i.g. rehydration. These data suggest that alpha 2 -adrenergic mechanism of the LPBN facilitates sodium/water retention and body fluid volume expansion during extracellular dehydration.
\end{abstract}

(c) 2016 Elsevier Ireland Ltd and Japan Neuroscience Society. All rights reserved.

\section{Introduction}

The lateral parabrachial nucleus (LPBN) integrates and relays taste and visceral signals that ascend from AP/mNTS to the forebrain areas involved in the control of fluid and electrolyte balance (Ciriello et al., 1984; Fulwiler and Saper, 1984; Herbert et al., 1990; Jhamandas et al., 1992; Jhamandas et al., 1996; Krukoff et al., 1993; Lanca and van der Kooy, 1985; Norgren, 1981). This bilateral pontine structure is responsible for important inhibitory mechanisms for the control of water and $\mathrm{NaCl}$ intake [for review see Andrade et al., 2014; Johnson and Thunhorst, 2007; Menani et al., 2014].

The alpha ${ }_{2}$-adrenoceptor/imidazoline receptor agonist moxonidine injected into the LPBN strongly enhances the sodium appetite of acutely sodium-depleted rats, but has no effect on sodium intake of hydrated and satiated rats (Andrade et al., 2004). Bilateral injections of noradrenaline or the specific $\alpha_{2}$-adrenoceptor agonist

\footnotetext{
* Corresponding author at: Rua Humaitá 1680, Araraquara, SP 14801-903, Brazil. Tel.: +55163301 6487; fax: +55 1633016488 .

E-mail address: carina.andrade@foar.unesp.br (C.A.F. Andrade).
}

alpha-methylnoradrenaline into the LPBN also increase sodium intake in sodium-depleted rats (Gasparini et al., 2009; Menani et al., 2006). These effects of moxonidine, noradrenaline and alpha-methylnoradrenaline were abolished by previous treatment with RX 821002, an $\alpha_{2}$-adrenoceptor antagonist, showing that alpha $_{2}$-adrenoceptor activation into the LPBN reduces inhibitory mechanisms of the LPBN that limit sodium intake (Andrade et al., 2014).

Although LPBN moxonidine injections failed to induce water or $0.3 \mathrm{M} \mathrm{NaCl}$ intake in satiated rats (Andrade et al., 2004), $\alpha_{2}$ adrenoceptor activation into the LPBN induces an unexpected strong ingestion of $0.3 \mathrm{M} \mathrm{NaCl}$ and reduces diuresis and natriuresis in hyperosmotic rats, enhancing the positive sodium balance (Andrade et al., 2006, 2012).

However, the effects of moxonidine injected into the LPBN on the urinary volume and sodium excretion were evaluated only in hyperosmotic rats, and its effects on renal responses, sodium balance and cardiovascular parameters in fluid-depleted rats during the sodium appetitive test remain unclear. Therefore, in the present study we investigated the importance of the LPBN on renal and cardiovascular responses induced by extracellular dehydration. 


\section{Materials and methods}

\subsection{Animals}

Male Wistar rats $(n=35)$ weighing $290-310$ g obtained from the Central Animal Facility of the Federal University of Alfenas (Alfenas-MG, Brazil) were used. The animals were housed in individual stainless steel cages with free access to food, water, and $1.8 \%$ $(0.3 \mathrm{M}) \mathrm{NaCl}$ solution. Temperature was maintained at $23 \pm 2{ }^{\circ} \mathrm{C}$, and humidity was maintained at $55 \pm 10 \%$ on a $12: 12$ light-dark cycle with light onset at 7:30 AM.

All procedures performed in studies involving animals were in accordance with the Ethical Committee for Animal Care and Use from Alfenas Federal University-Unifal-MG, Brazil (protocol no: 289/2010). The experimental protocols followed the recommendations of the Brazilian National Council for the Control of Animal Experimentation (CONCEA) and the U.S. National Institutes of Health Guide for the Care and Use of Laboratory Animals (NIH publication no. 80-23, 1996).

\subsection{LPBN cannulas}

Rats were anesthetized with ketamine $(80 \mathrm{mg} / \mathrm{kg}$ of body weight) combined with xylazine ( $7 \mathrm{mg} / \mathrm{kg}$ of body weight) and placed in a stereotaxic instrument (Insight EFF 331, Insight Instruments, Ribeirão Preto, Brazil). The surgery for bilateral LPBN cannula placements is described in earlies studies from our lab (Andrade et al., 2004., 2012, 2015).

\subsection{Injections into the $L P B N$}

Injections into the LPBN were made using 5- $\mu$ l Hamilton syringes connected by polyethylene tubing (PE-10) to 30-gauge injection cannulas. At time of testing, obturators were removed and the injection cannulas ( $2 \mathrm{~mm}$ longer than the guide cannulas) were introduced into the brain. The injection volume into the LPBN was $0.2 \mu \mathrm{l}$ each site. The obturators were replaced after injection, and the rats were placed back into the cage.

\subsection{Drugs}

Furosemide (FURO, Sigma Chem., St Louis, MO, USA) was administered subcutaneously at $10 \mathrm{mg} / \mathrm{kg}$ of body weight. Captopril (CAP, Sigma Chem., St Louis, MO, USA) was administered subcutaneously at $5 \mathrm{mg} / \mathrm{kg}$ of body weight. Moxonidine hydrochloride (Sigma Chem., St Louis, MO, USA) was administered into the LPBN at a dose of $0.5 \mathrm{nmol} / 0.2 \mu \mathrm{l}$. Moxonidine was dissolved in a mix of propylene glycol/water 2:1 (vehicle). Vehicle was injected as control into the LPBN. Captopril was dissolved in isotonic saline. Furosemide was dissolved in alkaline saline ( $\mathrm{pH}$ adjusted to 9.0 with $\mathrm{NaOH}$ ).

\subsection{Urine analyses}

Rats were housed in metabolic cages. Spontaneously eliminated urine was collected in $0.1-\mathrm{ml}$ graduated polypropylene tubes, and urinary volume was measured. The concentration of sodium and potassium in the urine was measured by a sodium and potassium sensitive electrode analyzer (Cobas B121, Roche, Rotkreuz, Switzerland). The amount of sodium and potassium in the urine was determined by the product of urine volume times the concentration of each ion in the urine. Sodium and water balance were calculated as the difference between the amount ingested (during the intake test or administered as gavage) and the amount excreted.

\subsection{Arterial pressure recording}

Under ketamine $(80 \mathrm{mg} / \mathrm{kg}$ of body weight) combined with xylazine ( $7 \mathrm{mg} / \mathrm{kg}$ of body weight) anesthesia, polyethylene tubing (PE-10 connected to a PE-50) was inserted into the abdominal aorta through the femoral artery on the day before the experiments. The tubing was tunneled s.c. and exposed on the back of the rat. Rats were tested in their home cages. The mean arterial pressure (MAP) was recorded in the unanesthetized freely moving rats using an amplifier coupled to a computerized acquisition system (MP100; Biopac System Inc., CA, USA).

\subsection{Experiment 1: moxonidine injection into the LPBN: urinary sodium excretion and urinary volume in fluid-depleted rats}

The main objective of this experiment was to verify the effects of alpha 2 -adrenergic activation in the LPBN on sodium excretion in fluid-depleted rats. Experiment 1 also provided behavioral parameters to guide Experiment 2.

Rats $(n=6)$ were habituated to metabolic cages at least one day prior to the experiments. During the experiment, water and sodium were removed and the animals were injected with furosemide (FURO) + captopril (CAP) treatment as described previously (Andrade et al., 2004; Fitts and Masson, 1989; Menani et al., 1996). Immediately after FURO + CAP treatment, a 0.1-ml graduated polypropylene tube was attached to each metabolic cage to allow urine sample collections. The first urine sample was collected $1 \mathrm{~h}$ after FURO + CAP treatment. The next samples were collected each $30 \mathrm{~min}$. Moxonidine or vehicle were bilaterally injected into the LPBN 45 min after FURO + CAP treatment. Rats were tested under two conditions: with and without free access to water and $0.3 \mathrm{M}$ $\mathrm{NaCl}$ during urine collection. Water and $0.3 \mathrm{M} \mathrm{NaCl}$ were available $1 \mathrm{~h}$ after FURO + CAP, provided from burettes with 0.1-ml divisions that were fitted with metal drinking spouts.

This group of rats was tested four times. In order to avoid any effect on sodium and water intake due to sensitization after multiple FURO + CAP treatments (Pereira et al., 2010), we controlled the experiments dividing the experimental groups and assigning the different treatments in a randomized way. In each test, the group was divided in two subgroups that received different treatments (vehicle or moxonidine into the LPBN combined with or without free access to water and $0.3 \mathrm{M} \mathrm{NaCl}$ ). The sequence of treatments in each rat in different tests was randomized and by the end of the tests, each rat had received all the treatments.

Sodium and water balance was calculated as the difference between the amount ingested ad libitum and the amount excreted.

\subsection{Experiment 2: moxonidine injection into the LPBN: sodium balance in fluid-depleted rats after i.g. rehydration}

The main objective of this experiment was to verify the effects of alpha ${ }_{2}$-adrenergic activation in the LPBN on sodium excretion and sodium balance in fluid-depleted rats after rehydration.

Rats $(n=7)$ were trained to the gavage procedure daily during at least 5 days. The training was performed once a day. The rat was held carefully and injected into the stomach with $1 \mathrm{ml}$ of water through PE-200 polyethylene tubing from a 5-ml syringe. Rats were also habituated to metabolic cages at least one day prior to the experiments.

During the experiment, water and sodium were removed and the animals were injected with furosemide (FURO)+captopril (CAP). Immediately after FURO + CAP treatment, a 0.1-ml graduated polypropylene tube was attached to each metabolic cage to allow urine sample collections. After $45 \mathrm{~min}$, moxonidine or vehicle were bilaterally injected into the LPBN. 
Rats then received intragastric loads of fluids to rehydrate the animals after FURO + CAP treatment in order to mimic moxonidine effects on water and $0.3 \mathrm{M} \mathrm{NaCl}$ in vehicle-treated rats. According to results of experiment 1 (see Fig. $2 \mathrm{C}$ and D), after LPBN moxonidine injections animals treated with FURO + CAP ingested about $7 \mathrm{ml} 0.3 \mathrm{NaCl}$ and $5 \mathrm{ml}$ water at $15 \mathrm{~min}$, followed by an additional of $4 \mathrm{ml} 0.3 \mathrm{M} \mathrm{NaCl}$ and $5 \mathrm{ml}$ water until $30 \mathrm{~min}$ of test. Mixing these amounts of $0.3 \mathrm{M} \mathrm{NaCl}$ and water ingested until 15 and until $30 \mathrm{~min}$ of the ingestive test, it was obtained $12 \mathrm{ml} 0.17 \mathrm{M} \mathrm{NaCl}$ and $9 \mathrm{ml}$ $0.13 \mathrm{M} \mathrm{NaCl}$, respectively. Thus, in this experiment rats received three consecutive intragastric gavages for rehydration $(6 \mathrm{ml} 0.17 \mathrm{M}$ $\mathrm{NaCl}$ at $5 \mathrm{~min}, 6 \mathrm{ml} 0.17 \mathrm{M} \mathrm{NaCl}$ at $15 \mathrm{~min}$ and $9 \mathrm{ml} 0.13 \mathrm{M} \mathrm{NaCl}$ at $30 \mathrm{~min}$ ) to produce controlled rehydration similar to moxonidine. These periods of 5,15 and $30 \mathrm{~min}$ is equivalent to the period elapsed after free access to fluids in experiment 1 (see Fig. 4 for details of timeline of these gavages).

The first urine sample was collected $1 \mathrm{~h}$ after FURO + CAP treatment. The next samples were collected each $30 \mathrm{~min}$. Sodium and water balance were calculated as the difference between the amount administered as gavage and the amount excreted.

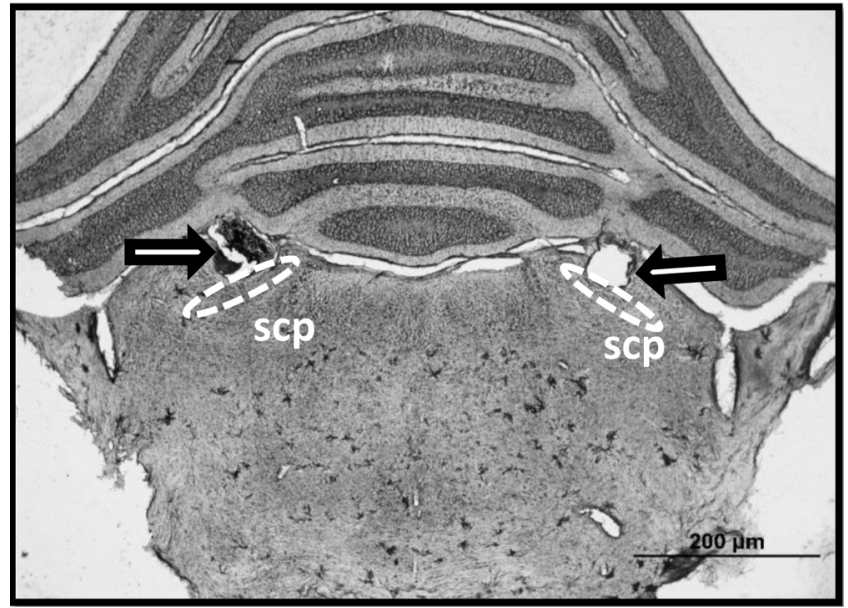

Fig. 1. Photomicrograph of a coronal section of a rat brain showing (arrows) the sites of bilateral injections into the LPBN. scp, superior cerebellar peduncle.

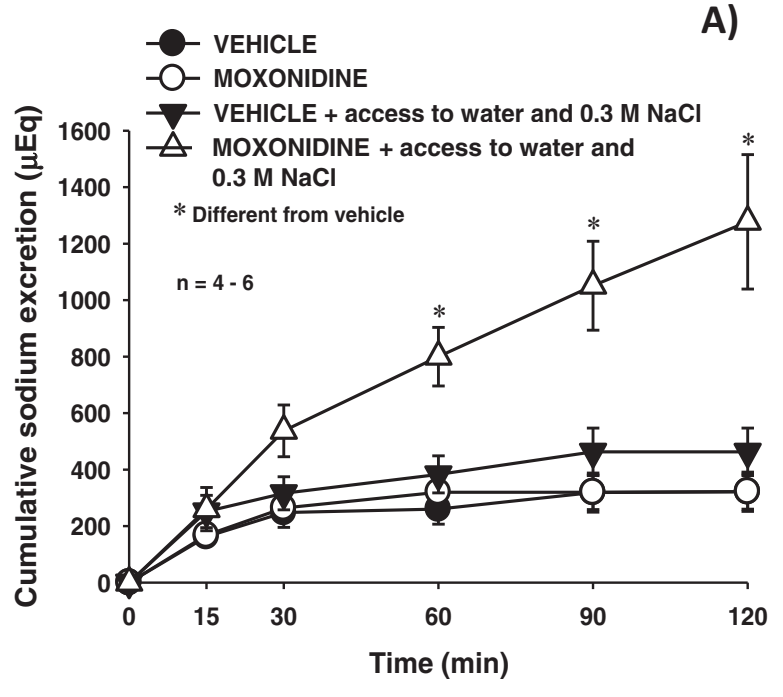

B)

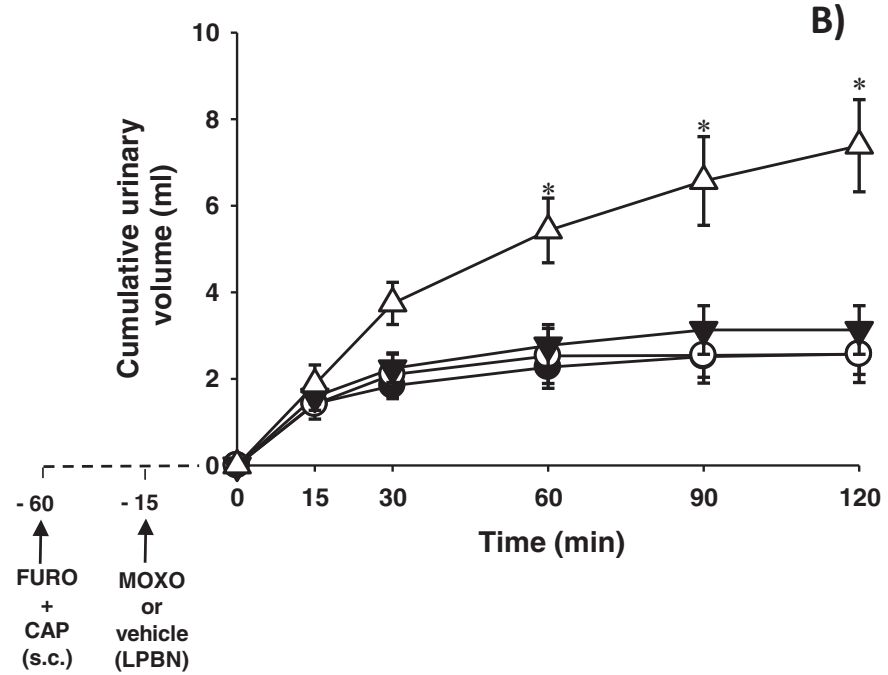

C)
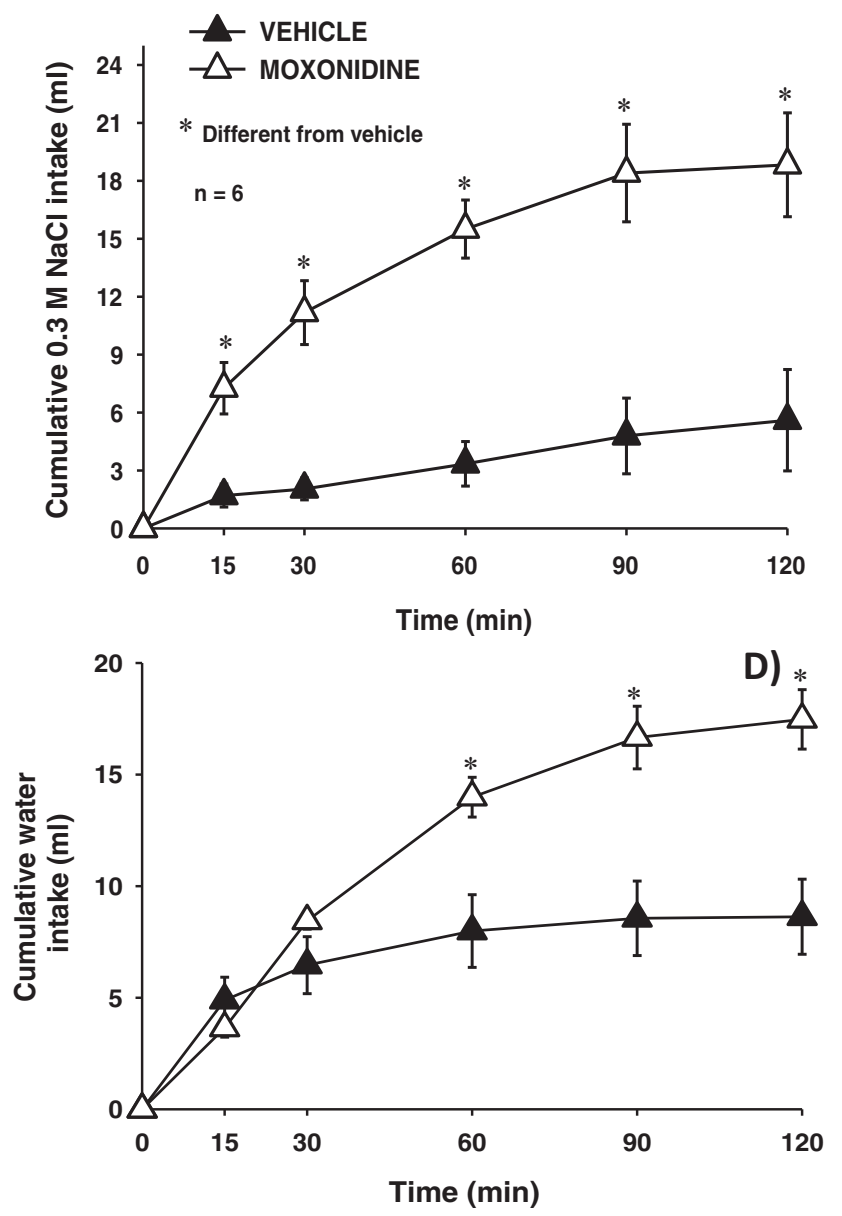

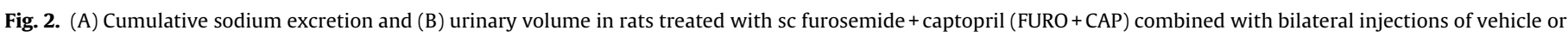

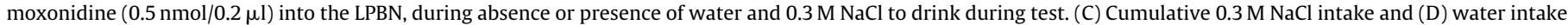

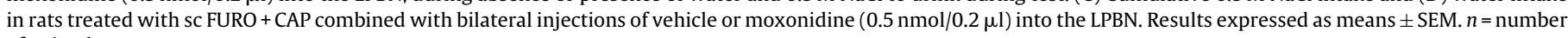
of animals. 
2.9. Experiment 3: moxonidine injection into the LPBN:

time-course arterial blood pressure and fluid intake recordings

The main objective of this experiment was to verify the effects of alpha $_{2}$-adrenergic activation in the LPBN on mean arterial pressure and heart rate in fluid-depleted rats during the ingestive test.

During the experiment, animals $(n=14)$ were kept in individual plastic chambers without food and fluids with the arterial cannula attached to the blood pressure recording system. Mean arterial pressure (MAP) and heart rate (HR) were recorded in unanesthetized freely moving rats. After a 30 -min period for baseline recording, animals were injected with FURO + CAP. After 45 min, moxonidine or vehicle was injected into the LPBN. Water and $0.3 \mathrm{M}$ $\mathrm{NaCl}$ were provided $15 \mathrm{~min}$ after LPBN injections for $2 \mathrm{~h}$. MAP and HR were recorded during all ingestive test.

Another group of rats $(n=8)$ was submitted to a similar protocol but without water and $0.3 \mathrm{M} \mathrm{NaCl}$ available to drink.

\subsection{Histology}

At the end of the tests, the animals were given bilateral injections of $2 \%$ Evans blue solution $(0.2 \mu \mathrm{l})$ into the LPBN. They were then deeply anesthetized with sodium thiopental $(80 \mathrm{mg} / \mathrm{kg}$ of body weight) and perfused transcardially with saline followed by $10 \%$ formalin. The brains were removed, fixed in $10 \%$ formalin, frozen, cut in 50- $\mu \mathrm{m}$ sections, stained with cresyl violet, and analyzed by light microscopy to confirm injection sites in the LPBN.

\subsection{Statistical analysis}

The results are reported as means \pm S.E.M. Two-way analysis of variance (ANOVA) using treatments and time as factors followed by the Newman-Keuls test for comparisons. Differences were considered significant if $p<0.05$.

\section{Results}

\subsection{Histological analysis}

Fig. 1 shows the typical sites of bilateral injections into the LPBN. The superior cerebellar peduncle (scp) is dotted as anatomical reference. The LPBN injections were centered mainly in the central lateral or dorsal lateral portions of the LPBN (Paxinos and Watson, 2004). Injections centered in the ventral lateral and external lateral portions, as well as in the Kölliker-Fuse nucleus observed in some rats were also considered as correctly placed in the LPBN. The sites of the injections in the present study were similar to those of previous studies that showed the effects of moxonidine injected into the LPBN on $\mathrm{NaCl}$ and water intake (Andrade et al., 2011, 2012, 2015)

\subsection{Experiment 1: Moxonidine injection into the LPBN: urinary} sodium excretion and urinary volume in fluid-depleted rats

Moxonidine injected bilaterally into the LPBN did not change urinary sodium excretion or urinary volume when compared to the LPBN vehicle injections in FURO + CAP treated rats that had no access to fluids. However, LPBN moxonidine injections in fluid-depleted rats with free access to fluids increased urinary sodium excretion $[F(3,110)=34.4 ; p<0.05]$ (Fig. $2 \mathrm{~A}$ ) and urinary volume $[F(3,115)=27.0 ; p<0.05]$ (Fig. $2 \mathrm{~B}$ ) when compared to vehicle treatment. When rats had free access to these fluids, bilateral LPBN moxonidine injections in fluid-depleted rats increased $0.3 \mathrm{M}$
A)
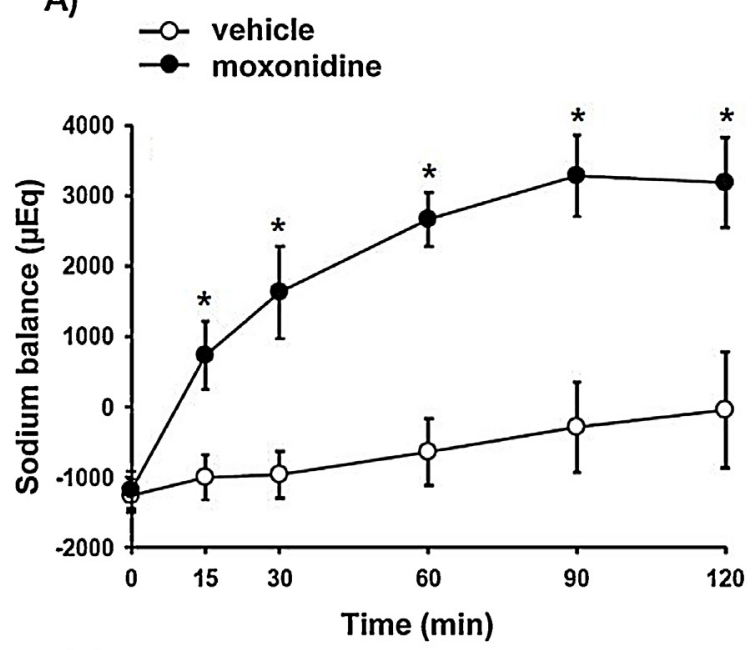

B)

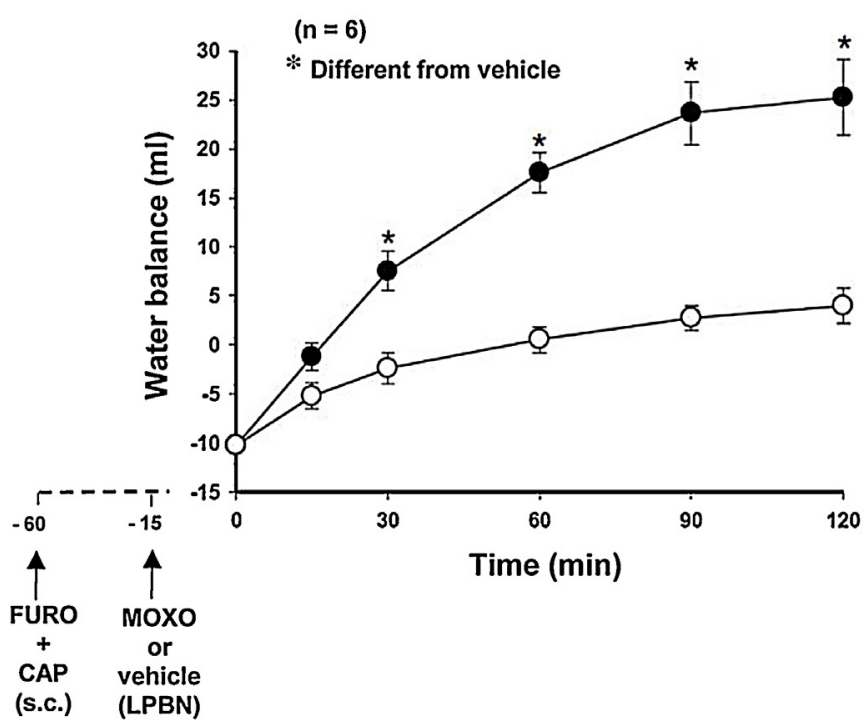

Fig. 3. (A) Sodium and (B) water balance in rats treated with sc furosemide + captopril (FURO + CAP) combined with bilateral injections of vehicle or moxonidine $(0.5 \mathrm{nmol} / 0.2 \mu \mathrm{l})$ into the $\mathrm{LPBN}$. Rats had free access to water and $0.3 \mathrm{M} \mathrm{NaCl}$ to drink during test. Results expressed as means \pm SEM. $n=$ number of animals.

$\mathrm{NaCl}$ intake $[F(1,60)=42.4 ; p<0.05]$ (Fig. 2C) and water intake $[F(1,60)=39.7 ; p<0.05]$ (Fig. 2D).

In order to evaluate if the increase in urinary excretion could be enough to counterbalance the increase in fluid intake, the difference between gain (amount ingested) and loss (amount excreted) of sodium and water was calculated. For this purpose, urinary excretion was measured from immediately after FURO + CAP treatment until the end of the ingestive test.

One hour after FURO + CAP treatment (a period that rats had no access to fluids), moxonidine and vehicle groups show similar renal loss of sodium and water (Fig. 3). After fluids were made available, rats with moxonidine injections into the LPBN showed an increase in sodium $[F(1,72)=65.2 ; p<0.05]$ and water gain $[F(1,72)=117.1$; $p<0.05$ ] in comparison to vehicle treatment during all test. Note that while the control group (vehicle into the LPBN) reached normal sodium and water balance at the end of the ingestive test, the moxonidine group retained more sodium and water until the end of the ingestive test (Fig. 3). 

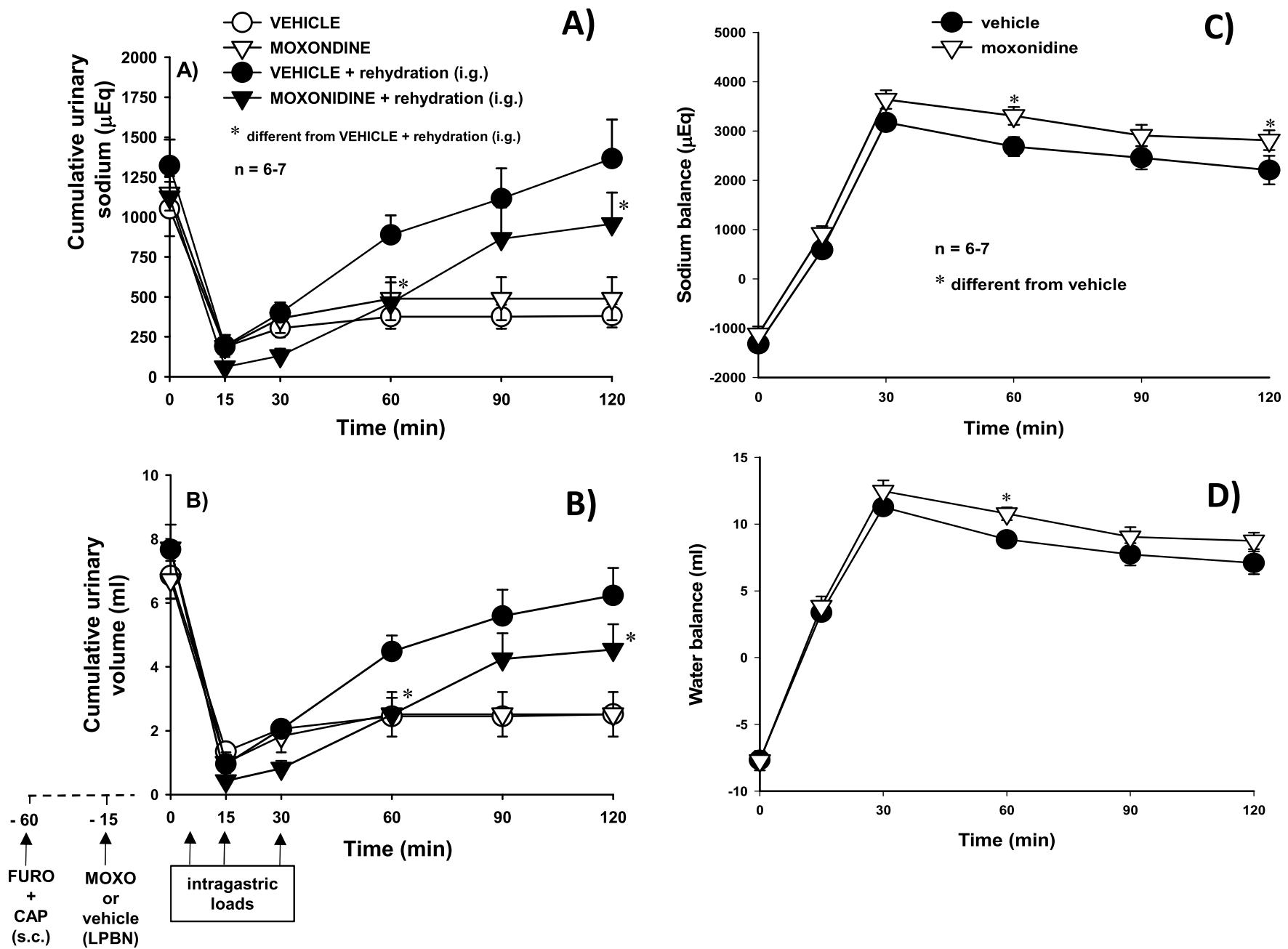

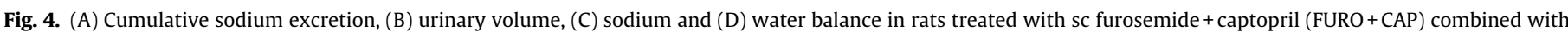

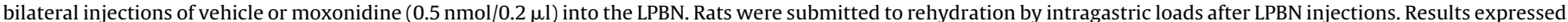
as means \pm SEM. $n=$ number of animals.

\subsection{Experiment 2: moxonidine injection into the LPBN: sodium balance in fluid-depleted rats after i.g. rehydration}

One hour after FURO + CAP treatment (a period that rats had no access to fluids), moxonidine and vehicle groups showed similar renal loss of sodium and water (Fig. 4). In rats submitted to controlled rehydration after FURO-CAP treatment, LPBN moxonidine injections decreased urinary sodium excretion $[F(3,126)=12.81$; $p<0.05$ ] (Fig. 4A) and urinary volume $[F(3,126)=12.81 ; p<0.05]$ (Fig. 4B) at 60 and $120 \mathrm{~min}$ of the test.

Both group of rats submitted to controlled rehydration after FURO-CAP treatment showed a gain of sodium bigger than the renal excretion at $30 \mathrm{~min}$ of the test, but moxonidine rats continued to retain more sodium and water than control treated rats, $([F(1,66)=16.003 ; p<0.05]$, Fig. $4 C$ and $([F(1,72)=8.336 ; p<0.05]$, Fig. 4D, respectively).

\subsection{Experiment 3: moxonidine injection into the $L P B N$ : time-course arterial blood pressure and fluid intake recordings}

ANOVA showed differences between treatments for MAP $[F(3,153)=11.14 ; p<0.05]$ and $\operatorname{HR}[F(3,133)=23.7 ; p<0.05]$. In comparison with vehicle treated rats, MAP and HR were higher in rats that received moxonidine injections into the $L P B N$, irrespective of access to fluids, Fig. 5.
During cardiovascular recording moxonidine injections into the LPBN in rats with free access to fluids increased $0.3 \mathrm{M} \mathrm{NaCl}$ intake $(25.5 \pm 5 \mathrm{ml} / 120 \mathrm{~min}$ vs. vehicle: $4.3 \pm 1.4 \mathrm{ml} / 120 \mathrm{~min}$, $[F(1,72)=72.267 ; \quad p<0.05])$. No changes were observed in FURO + CAP-induced water intake $(18.8 \pm 5 \mathrm{ml} / 120 \mathrm{~min}$ vs. vehicle: $15.4 \pm 1.0 \mathrm{ml} / 120 \mathrm{~min},[F(1,72)=0.06 ; p>0.05]$.

\section{Discussion}

We found that bilateral moxonidine injections into the LPBN increased sodium retention in fluid-depleted rats after free access to water and $0.3 \mathrm{M} \mathrm{NaCl}$. Bilateral LPBN moxonidine injections did not change sodium excretion and urinary volume in fluid-depleted rats without access to water and $0.3 \mathrm{M} \mathrm{NaCl}$. However, LPBN moxonidine decreased sodium excretion and urinary volume under conditions of controlled rehydration. LPBN moxonidine injections increased mean arterial pressure in fluid-depleted rats with or without access to water and $0.3 \mathrm{M} \mathrm{NaCl}$. Taken together, these results suggest that the $L P B N$ has an important role in hydro mineral balance during extracellular dehydration.

Acute fluid-depletion was induced by FURO + CAP (Fitts and Masson, 1989; Menani et al., 1996; Thunhorst and Johnson, 1994). The rapid induction of water and $0.3 \mathrm{M} \mathrm{NaCl}$ intake by FURO + CAP results from the association of mild hypotension $(-5 \mathrm{~mm} \mathrm{Hg}$, in the rats tested in the present study) and less activation of low-pressure 

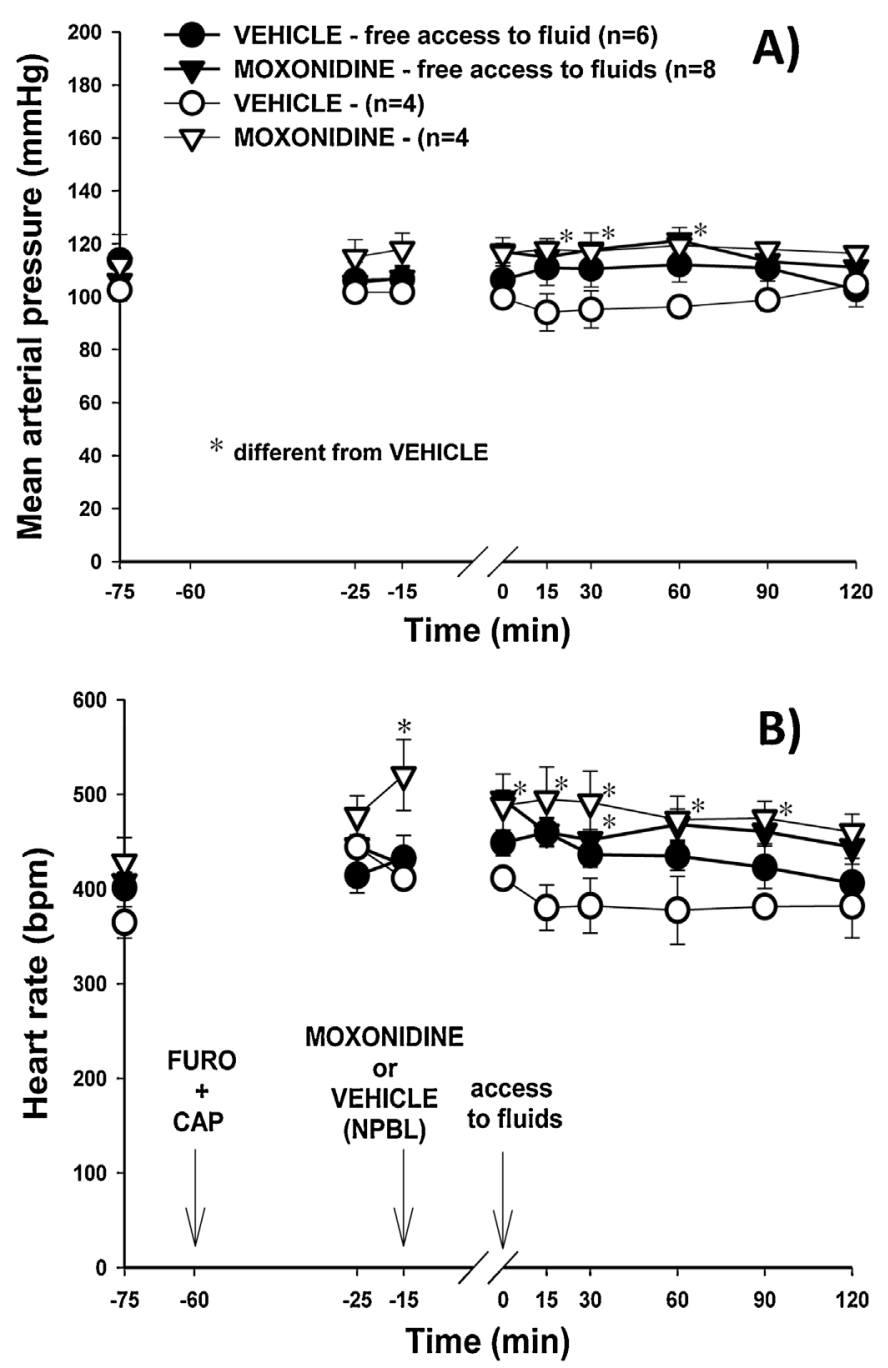

Fig. 5. (A) Mean arterial pressure and (B) heart rate after moxonidine $(0.5 \mathrm{nmol} / 0.2 \mu \mathrm{l})$ or vehicle injections into the LPBN in FURO + CAP-treated rats with (white symbols) and without access (dark symbols) to fluids to drink.

volume receptors plus increased ANG II formation in brain (Fitts and Masson, 1989; Thunhorst and Johnson, 1994).

Moxonidine injections into the LPBN did not change urinary volume and urinary sodium excretion in FURO + CAP-treated rats without access to fluids during the test. In contrast to when the rats had access to water and $0.3 \mathrm{M} \mathrm{NaCl}$, this increase in sodium and water excretion after access to fluids is probably a volume expansion induced by massive intake of sodium and water. That is why the increase in sodium and water excretion is observed about $30 \mathrm{~min}$ after drinking significant amounts of sodium and water. However, a detailed analysis of renal mechanisms during fluid access was not performed.

In experiment 1 , rats treated with moxonidine into the LPBN ingested about $11 \mathrm{ml}$ of $0.3 \mathrm{M} \mathrm{NaCl}$ and $10 \mathrm{ml}$ of water during the first $30 \mathrm{~min}$ of the test, while vehicle-treated rats ingested about $3 \mathrm{ml}$ of $0.3 \mathrm{M} \mathrm{NaCl}$ and about $5 \mathrm{ml}$ of water during the same period. In order to compare vehicle and moxonidine treated rats to the same experimental rehydration condition, another group of rats received intragastric (i.g.) loads to mimic the amount of sodium and water that would be ingested only by LPBN moxonidine-treated rats. Therefore, in experiment 2 , FURO + CAP-treated rats with no access to fluids during the test were rehydrated by intragastric loads (as described in item 2.8). Under controlled rehydration after FURO-CAP treatment, LPBN moxonidine injections decreased urinary sodium excretion and urinary volume when compared to vehicle injections into the LPBN. Although both groups showed similar increased sodium and water gain at $30 \mathrm{~min}$ of the test, moxonidine treated rats continued to exhibit a higher sodium and water retention than control rats over the test period. Thus, these results suggest that moxonidine injections into the LPBN reduce renal sodium and water excretion during rehydration after extracellular dehydration.

Despite its anti-hypertensive effect through activation of imidazoline receptors in the rostroventrolateral medulla (Ernsberger et al., 1993, 1997; Haxhiu et al., 1994), moxonidine injected into the LPBN did not alter arterial pressure or heart rate in either normovolemic control animals or $1 \mathrm{~h}$ after FURO + CAP treatment (Andrade et al., 2004). The present results corroborate previous data, showing that LPBN moxonidine injections did not change MAP in FURO + CAP-treated rats with or without access to fluids when compared to basal recording period. However, both group of rats treated with moxonidine showed increased MAP. Therefore, the enhancement of $0.3 \mathrm{M} \mathrm{NaCl}$ intake after moxonidine injections into the LPBN in FURO + CAP-treated rats is not due to changes in arterial pressure after FURO + CAP treatment. On the other hand, the increase in $0.3 \mathrm{M} \mathrm{NaCl}$ and water intake induced by LPBN moxonidine injections also did not cause any further increase in MAP when compared to rats treated with moxonidine without access to fluids.

The role of LPBN in modulating renal and hormonal responses was previously studied under conditions of isotonic blood volume expansion and during increased plasma osmolarity. In the early study, Margatho et al. (2007) showed that LPBN serotonergic blockade attenuated the increase in sodium and potassium excretion and urinary volume, as well as, the increase in ANP, OT and AVP induced by isotonic blood volume expansion in hydrated rats, while serotonergic activation produced the opposite effects (Margatho et al., 2007).

In response to increased plasma osmolarity, bilateral injections of moxonidine into the LPBN produced a decrease in diuresis and natriuresis, as well as a reduction in the increase in plasma oxytocin (OT) without changes in blood volume (Andrade et al., 2012). Oxytocin facilitates renal sodium excretion [for a review, see Antunes-Rodrigues et al., 2004] and OT centrally may also activate inhibitory mechanisms for sodium intake (Blackburn et al., 1992, 1995). Therefore, reductions in plasma levels of this hormone might reduce increased plasma osmolarity-induced natriuresis and may disinhibit sodium intake.

Taken together, these previous studies suggest that the LPBN is important to modulate behavioral, renal and hormonal responses to increased sodium balance under conditions of isotonic blood expansion and increased plasma osmolality (Andrade et al., 2012; Margatho et al., 2007). The present study extends this concept, showing that during acute fluid depletion induced by FURO + CAP treatment, moxonidine increased sodium balance during free access to water and $0.3 \mathrm{M} \mathrm{NaCl}$ and decreased urinary volume and sodium excretion and increased sodium and water balance in FURO + CAP-treated rats submitted to i.g. rehydration. Therefore, the LPBN is important to avoid excessive sodium and water intake further than the necessary to restore hydro mineral balance.

The presence of alpha 2 -adrenoceptors in the LPBN (Herbert and Flugge, 1995; Talley et al., 1996), mainly in the external LPBN and the waist area of the parabrachial nucleus (Herbert and Flugge, 1995), is consistent with the pattern of ascending axons from the $\mathrm{AP} / \mathrm{mNTS}$ terminating in the parabrachial nucleus (Herbert et al., 1990). Visceral and gustatory signals that ascend to the NTS make a second relay in the PBN prior to projecting to the forebrain. Saleh and Cechetto (1994) showed that injections of the alpha $_{2}$-adrenoceptor antagonist yohimbine into the LPBN resulted in a $77 \%$ inhibition of spontaneous activity of visceral responsive neurons in the ventral basal thalamus, suggesting that 
alpha $_{2}$-adrenoceptors in the LPBN may modulate the visceral sensory information that ascends from $\mathrm{AP} / \mathrm{mNTS}$ to the visceral forebrain (Saleh and Cechetto, 1994). The present results suggest alpha $_{2}$-adrenergic/imizadoline receptor activation in the LPBN activates behavioral and renal mechanisms that facilitate sodium/water retention and body fluid volume expansion during extracellular dehydration. Therefore, the lateral parabrachial nucleus may modulate behavioral and renal responses to counter body fluid volume expansion.

\section{Acknowledgments}

The authors thank MF Venâncio and J dos Reis Pereira (UnifalMG) for technical assistance. This research was supported by Brazilian public funding from Fundação de Amparo à Pesquisa do Estado de Minas Gerais (FAPEMIG), Conselho Nacional de Desenvolvimento Científico e Tecnológico (CNPq) and CAPES. This work was part of the requirements to obtain a Master degree by Kriss A. Cabral in the Graduate Program in Physiology of the Brazilian Physiological Society (Programa Multicêntrico de Pós-Graduação em Ciências Fisiológicas, Unifal-MG, Sociedade Brasileira de Fisiologia - SBFis), Brazil.

\section{References}

Andrade, C.A., Andrade-Franze, G.M., De Luca Jr., L.A., Johnson, A.K., Menani, J.V., 2011. Changes in taste reactivity to intra-oral hypertonic $\mathrm{NaCl}$ after lateral parabrachial injections of an alpha2-adrenergic receptor agonist. Physiol. Behav. 104, 702-708.

Andrade, C.A., Andrade-Franze, G.M., De Paula, P.M., De Luca Jr., L.A., Menani, J.V., 2014. Role of alpha2-adrenoceptors in the lateral parabrachial nucleus in the control of body fluid homeostasis. Braz. J. Med. Biol. Res. 47, 11-18.

Andrade, C.A., Barbosa, S.P., De Luca Jr., L.A., Menani, J.V., 2004. Activation of alpha2adrenergic receptors into the lateral parabrachial nucleus enhances $\mathrm{NaCl}$ intake in rats. Neuroscience $129,25-34$

Andrade, C.A., De Luca Jr., L.A., Colombari, D.S., Menani, J.V., 2006. Alpha2-adrenergic activation in the lateral parabrachial nucleus induces $\mathrm{NaCl}$ intake under conditions of systemic hyperosmolarity. Neuroscience 142, 21-28.

Andrade, C.A., Margatho, L.O., Andrade-Franze, G.M., De Luca Jr., L.A., AntunesRodrigues, J., Menani, J.V., 2012. Moxonidine into the lateral parabrachial nucleus reduces renal and hormonal responses to cell dehydration. Neuroscience 208, 69-78.

Andrade, C.A.F., Oliveira, L.B.D., Andrade-Franzéa, G.M.F., De Luca Jr., L.A., Colombari, D.S.A., Menani, J.V., 2015. Gabaergic and opioid receptors mediate the facilitation of $\mathrm{NaCl}$ intake induced by $\alpha 2$-adrenergic activation in the lateral parabrachial nucleus. Behav. Brain Res. 278, 535-541.

Antunes-Rodrigues, J., de Castro, M., Elias, L.L., Valenca, M.M., McCann, S.M., 2004. Neuroendocrine control of body fluid metabolism. Physiol. Rev. 84, $169-208$.

Blackburn, R.E., Demko, A.D., Hoffman, G.E., Stricker, E.M., Verbalis, J.G., 1992. Central oxytocyn inhibition of angiotensin-induced salt appetite in rats. Am. J. Physiol. 263, R1347-R1353.

Blackburn, R.E., Samson, W.K., Fulton, R.J., Stricker, E.M., Verbalis, J.G., 1995. Central oxytocin and ANP receptors mediate osmotic inhibition of salt appetite in rats. Am. J. Physiol. 269, R245-R251.

Ciriello, J., Lawrence, D., Pittman, Q.J., 1984. Electrophysiological identification of neurons in the parabrachial nucleus projecting directly to the hypothalamus in the rat. Brain Res. 322, 388-392.
Ernsberger, P., Damon, T.H., Graff, L.M., Schafer, S.G., Christen, M.O., 1993. Moxonidine, a centrally acting antihypertensive agent, is selective ligant for $\mathrm{I}_{1}$-imidazoline sites. J. Pharmacol. Exp. Therap. 264, 172-264.

Ernsberger, P., Friedman, J.E., Koletski, R.J., 1997. The $\mathrm{I}_{1}$-imidazoline receptor: from binding site to therapeutic target in cardiovascular disease. Hypertension 15, S9-S23.

Fitts, D.A., Masson, D.B., 1989. Forebrain sites of action for drinking and salt appetite to angiotensin or captopril. Behav. Neurosci. 103, 865-872.

Fulwiler, C.E., Saper, C.B., 1984. Subnuclear organization of the efferent connections of the parabrachial nucleus in the rat. Brain Res. 319, 229-259.

Gasparini, S., de Luca Jr., L.A., Colombari, D.S., de Paula, P.M., Barbosa, S.P., Menani, J.V., 2009. Adrenergic mechanisms of the Kolliker-Fuse/A7 area on the control of water and sodium intake. Neuroscience 164, 370-379.

Haxhiu, M.A., Dreshaj, I., Schafer, S.G., Ensberger, P., 1994. Selective antihypertensive action of moxonidine is mediated mainly by $\mathrm{I}_{1}$-imidazoline receptors in the rostral ventrolateral medulla. J. Cardiovasc. Pharmacol. 24, S1-S8.

Herbert, H., Flugge, G., 1995. Distribution of alpha 2-adrenergic binding sites in the parabrachial complex of the rat. Anat. Embryol. (Berl.) 192, 507-516.

Herbert, H., Moga, M.M., Saper, C.B., 1990. Connections of the parabrachial nucleus with the nucleus of the solitary tract and the medullary reticular formation in the rat. J. Comp. Neurol. 293, 540-580.

Jhamandas, J.H., Harris, K.H., Petrov, T., Krukoff, T.L., 1992. Characterization of the parabrachial nucleus input to the hypothalamic paraventricular nucleus in the rat. J. Neuroendocrinol. 4, 461-471.

Jhamandas, J.H., Petrov, T., Harris, K.H., Vu, T., Krukoff, T.L., 1996. Parabrachial nucleus projection to the amygdala in the rat: electrophysiological and anatomical observations. Brain Res. Bull. 39, 115-126.

Johnson, A.K., Thunhorst, R.L., 2007. The neuroendocrinology, neurochemistry and molecular biology of thirst and salt appetite. In: Lajtha, A., Laustein, J. (Eds.) Handbook of Neurochemistry and Molecular Neurobiology: Behavioral Neurochemistry, Neuroendocrinology and Molecular Neurobiology. , 3rd ed. Springer, New York, pp. 641-687.

Krukoff, T.L., Harris, K.H., Jhamandas, J.H., 1993. Efferent projections from the parabrachial nucleus demonstrated with the anterograde tracer Phaseolus vulgaris leucoagglutinin. Brain Res. Bull. 30, 163-172.

Lanca, A.J., van der Kooy, D., 1985. A serotonin-containing pathway from the area postrema to the parabrachial nucleus in the rat. Neuroscience 14, 1117-1126.

Margatho, L.O., Giusti-Paiva, A., Menani, J.V., Elias, L.L.K., Vivas, L.M., AntunesRodrigues, J., 2007. Serotonergic mechanisms of the lateral parabrachial nucleus in renal and hormonal responses to isotonic blood volume expansion. Am. J. Physiol. Regul. Integr. Comp. Physiol. 292, R1190-R1197.

Menani, J., Oliveira, L., Andrade, C.A.F., Sugawara, A., De Luca Jr., L., 2006. Role of Central alpha2-adrenergic/imidazoline receptors in the control of thirst, sodium appetite and renal excretion. In: Chen, F. (Ed.), New Trends in Brain Research. Nova Science Publishers, Inc., New York, pp. 95-126.

Menani, J.V., De Luca Jr., L.A., Johnson, A.K., 2014. Role of the lateral parabrachial nucleus in the control of sodium appetite. Am. J. Physiol. Regul. Integr. Comp. Physiol. 306, R201-R210.

Menani, J.V., Thunhorst, R.L., Johnson, A.K., 1996. Lateral parabrachial nucleus and serotonergic mechanisms in the control of salt appetite in rats. Am. J. Physiol. 270, R162-R168.

Norgren, R., 1981. The central organization of the gustatory and visceral systems in the nucleus of the solitary tract. In: Katsuki, Y., Norgren, R., Sato, M. (Eds.), Brain Mechanisms of Sensation. Wiley, New York, pp. 143-160.

Paxinos, G., Watson, C., 2004. The Rat Brain in Stereotaxic Coordinates, 5th ed. Academic Press, San Diego, CA.

Pereira, D.T., Menani, J.V., De Luca Jr., L.A., 2010. FURO/CAP: a protocol for sodium intake sensitization. Physiol. Behav. 99, 472-481.

Saleh, T.M., Cechetto, D.F., 1994. Neurotransmitters in the parabrachial nucleus mediating visceral input to the thalamus in rats. Am. J. Physiol. 266, R1287-R1296

Talley, E.M., Rocin, D.L., Lee, A., Guyenet, P.G., Lynch, K.R., 1996. Distribution of alpha $2 \mathrm{~A}$-adrenergic receptor-like immunoreactivity in the rat central nervous system. J. Comp. Neurol. 372, 111-134.

Thunhorst, R.L., Johnson, A.K., 1994. Renin-angiotensin, arterial blood pressure, and salt appetite in rats. Am. J. Physiol. 266, R458-R465. 